\title{
Impact of including the plume rise of vegetation fires in numerical simulations of associated atmospheric pollutants
}

\author{
S. R. Freitas, ${ }^{1}$ K. M. Longo, ${ }^{1}$ and M. O. Andreae ${ }^{2}$ \\ Received 17 April 2006; revised 15 June 2006; accepted 31 July 2006; published 8 September 2006.
}

[1] We investigate the importance of including in lowresolution atmospheric models the plume rise associated with the strong buoyancy of hot gases from vegetation fires. This sub-grid transport mechanism is simulated by embedding a 1D cloud resolving model, with appropriate lower boundary conditions, in each column of a 3D host model. Remote-sensing fire products are used in combination with a land use dataset for selection of appropriate fire properties. The host model provides the environmental conditions, and the plume rise is simulated explicitly. The final height of the plume is then used in the source emission field of the host model to determine the effective injection height, and the material emitted during the flaming phase is released at this height. Model results are compared with $500 \mathrm{hPa}$ AIRS carbon monoxide (CO) data for September 2002 and with CO aircraft profiles from the SMOCC campaign, showing the huge impact on model performance. Citation: Freitas, S. R., K. M. Longo, and M. O. Andreae (2006), Impact of including the plume rise of vegetation fires in numerical simulations of associated atmospheric pollutants, Geophys. Res. Lett., 33, L17808, doi:10.1029/ 2006GL026608.

\section{Introduction}

[2] In spite of the continuous increase in computing power, we are still far from being capable of running atmospheric models, including chemistry or not, that take into account explicitly all the relevant motion scales. Therefore, current atmospheric chemistry models use several types of parameterizations in order to include the subgrid transport and processes to resolve the mass continuity equation of the chemical species. The most common subgrid transport parameterizations include diffusion in the boundary layer and convective transport associated with moist circulation. However, for biomass burning emissions the strong updrafts associated with the initial buoyancy can have a huge impact on tracer distribution through a direct and rapid transport into the free troposphere as well as the stratosphere [Lavoué et al., 2000; Andreae et al., 2001; Fromm and Servranckx, 2003; Colarco et al., 2004; Jost et al., 2004; Luderer et al., 2006]. This mechanism cannot be resolved explicitly by the current large-scale models and it is frequently ignored.

[3] Here we present a way to include this sub-grid transport by embedding a 1D cloud resolving model, with

\footnotetext{
${ }^{1}$ Center for Weather Forecasting and Climate Studies, Instituto Nacional de Pesquisas Espaciais, Sao Paulo, Brazil.

${ }^{2}$ Max Planck Institute for Chemistry, Mainz, Germany.

Copyright 2006 by the American Geophysical Union. 0094-8276/06/2006GL026608\$05.00
}

appropriate lower boundary conditions, in each column of a 3D host model. First we give a brief description of the relevant typical parameters associated with biomass burning. Next the methodology is described, and then we show comparisons of model simulations with AIRS $500 \mathrm{hPa}$ carbon monoxide [McMillan et al., 2005] and aircraft CO profiles from the SMOCC 2002 (Smoke Aerosols, Clouds, Rainfall and Climate) campaign.

\section{Biomass Burning and Some Estimated Plume Rise Characteristics}

[4] Biomass burning emits hot gases and particles, which are transported upward due to positive buoyancy. The interaction between the smoke and the environment produces eddies that entrain colder environmental air into the smoke plume, which dilutes the plume and reduces buoyancy. The final plume height is mostly controlled by the thermodynamic stability of the ambient atmosphere. This mechanism has a strong impact on pollutant dispersion, since in the free troposphere the pollutants are advected away faster from the source region. Removal processes are more efficient in the planetary boundary layer (PBL); when the pollutants are transported to the free troposphere their residence time increases. In order to illustrate this mechanism, Figure 1 shows the plume rise associated with a deforestation fire in the State of Rondônia, Brazil, during the SMOCC campaign.

[5] A key piece of information for modeling plume rise is the heat flux associated with the vegetation fires. The heat flux from biomass burning is highly variable, and mainly related to the fuel load, fuel water content, and weather conditions. Based on several published data sets [Miranda et al., 1993; Carvalho et al., 1995, 2001; Ferguson et al., 2000; Ward et al., 1992; Riggan et al., 2004] all possible classes of vegetation burning were aggregated into three main types: tropical forest, woody savanna and grassland; then for each type a lower and upper heat flux limit was estimated (Table 1). For tropical forest, the estimated lower and upper limit was 30 and $80 \mathrm{~kW} \mathrm{~m}^{-2}$, respectively. This is consistent with Trentmann et al. [2002] where the authors estimated a total energy emission of about $5500 \mathrm{MW}$ during the flaming phase for a 19.4 ha prescribed forest fire in the United States, giving a mean of $28 \mathrm{~kW} \mathrm{~m}^{-2}$. For grassland, due to the scarcity of data, only one heat flux could be estimated. Table 1 also includes the typical fraction of the biomass consumed during the flaming phase.

[6] Fire size is another piece of information needed for plume rise and emission calculations. This quantity will modulate the total heat, smoke, and water fluxes into the atmosphere. Thinner plumes have more entrainment and are more easily broken by the ambient eddies. The remote 


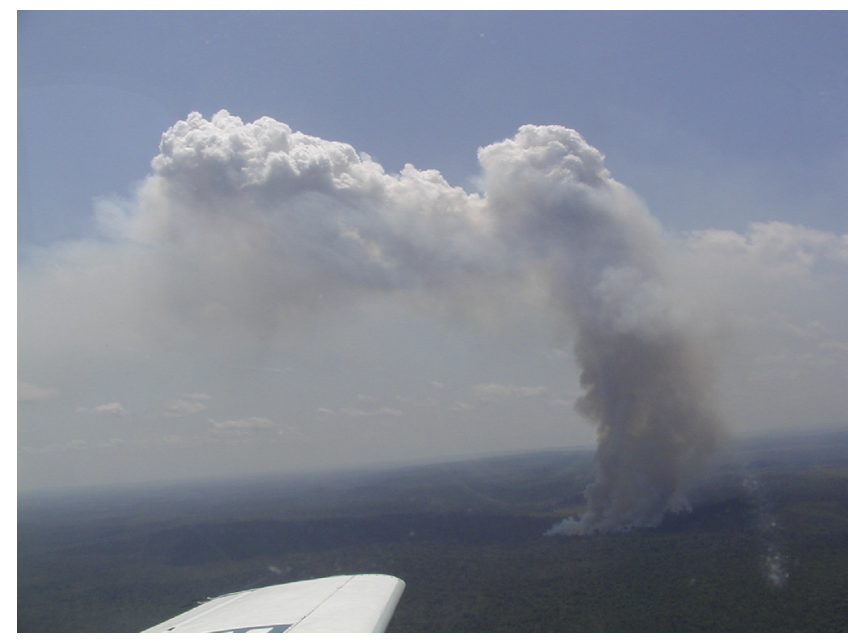

Figure 1. Photograph of the smoke plume rise produced from a deforestation fire in the Amazon basin.

sensing fire product GOES-8 WF_ABBA (Wild Fire Automated Biomass Burning Algorithm [Prins et al., 1998]) has been used to provide the fire location and the instantaneous fire size for each non-saturated and non-cloudy fire pixel, where it is possible to retrieve sub-pixel fire characteristics.

\section{Methodology}

[7] The plume rise associated with vegetation fires is explicitly simulated using a simple one-dimensional timedependent entrainment plume model [Latham, 1994]. The equations are based on the first law of thermodynamics and the vertical equation of motion. The equation for the vertical velocity follows very closely the approach of Simpson and Wiggert [1969]. Cloud microphysical calculations are based on the Kessler [1969] parameterization for accretion, and include ice formation according to Ogura and Takahashi [1971]. Autoconversion is performed following the Berry [1968] formulation. In our case, the initial number concentration of cloud condensation nuclei is defined as $10^{5} \mathrm{~cm}^{-3}$, as described by Andreae et al. [2004] for pyro-CB. Entrainment of environmental air is taken to be proportional to the vertical velocity in the air, and the entrainment coefficient is based on the traditional approach $2 \alpha \mathrm{R}^{-1}$ where R stands for the radius of the plume and $\alpha=0.1$.

[8] Scalar fields are advected using a forward-upstream scheme of second order, while for wind a standard leapfrogtype scheme is used [Tremback et al., 1987]. The lower boundary condition is based on a virtual source of buoyancy placed below the model surface [Turner, 1973]. The buoyancy generated by this source is obtained from the energy flux and area of the fire, which are derived in the following way. For each grid column, by merging the fire location with the land use dataset, all fires are aggregated into three categories: forest, woody savanna, and grassland. For each category, two energy fluxes (lower and upper bounds) are defined according to Table 1 and using the McCarter and Broido [1965] factor of 0.55 to convert heat flux into convective energy. The area of fire is defined from the simple mean of the instantaneous size, as estimated by WF_ABBA, of all fires that belong to the same category. For $\overline{W F}$ _ABBA detected fires for which there is no information about the instantaneous fire size, the mean instantaneous fire size of 20 ha (calculated from the total data set of the previous years) is used. Once the buoyancy flux is determined, it provides the vertical velocity and the temperature excess for the air parcel at the surface according to Morton et al. [1956] and Latham [1994]. The water vapor excess is calculated using $0.5 \mathrm{~kg} \mathrm{H}_{2} \mathrm{O}$ per kg dry fuel as the emission factor for water. The upper boundary condition is defined by a Rayleigh friction layer with $60 \mathrm{~s}$ timescale, which relaxes wind and temperature toward the undisturbed reference state values. The model grid space resolution is $100 \mathrm{~m}$, with the top at $20 \mathrm{~km}$ height. The model timestep is dynamically calculated following the Courant-FriedrichLewy stability criterion, and does not exceed 5 seconds. The microphysics is resolved with time splitting $(1 / 3$ of dynamic time step). Typically the steady state is reached within 50 minutes, this number being the upper limit of the time integration.

[9] The 1D plume model is embedded in each column of a $3 \mathrm{D}$ host model. In this technique, the $3 \mathrm{D}$ model feeds the plume model with the ambient conditions. Since this technique has been applied to low-resolution 3D models (grid scale $\sim 40-100 \mathrm{~km}$ ), it has been assumed that the fires have no significant effect on the dynamics and the thermodynamics at this scale. It only affects the source emission field through the height, where the tracers emitted during the flaming phase are released into the 3D model. The 3D model used in this study is the Coupled Aerosol and Tracer Transport model to the Brazilian developments on the Regional Atmospheric Modeling System (CATT-BRAMS [Freitas et al., 2005]).

[10] The outline of this technique is as follows. (1) A 1D CRM embedded in each column of the large-scale atmospheric-chemistry transport model and appropriate lower boundary conditions are used. (2) For each grid box with fires, the large-scale condition of the host model is passed to the 1D CRM. (3) The motion of the plume for each fire category and flux energy is resolved explicitly, defining the lower and upper injection height. (4) The lower and upper limits of the final rise of the plume are returned to the host model. (5) This plume rise is taken into account in the source emission field releasing material emitted during the flaming phase in the vertical range delimited by the lower and upper heights.

[11] Carbon monoxide ( $\mathrm{CO})$ measurements during SMOCC were obtained on the INPE Bandeirante aircraft using an Aero-Laser (AL5002) instrument operating at $1 \mathrm{~Hz}$. The measurement accuracy is better than $\pm 5 \%$; details are given by Guyon et al. [2005].

\section{Model Results}

[12] Model simulations were performed for the 2002 dry season, and model results were compared with obser-

Table 1. Lower and Upper Limits for the Heat Flux and Fraction of Biomass Consumed in the Flaming Phase

\begin{tabular}{lccc}
\hline \multicolumn{1}{c}{ Biome type } & $\begin{array}{c}\text { Lower } \\
\text { Limit, } \\
\mathrm{kW} \mathrm{m}^{-2}\end{array}$ & $\begin{array}{c}\text { Upper } \\
\text { Limit, } \\
\mathrm{kW} \mathrm{m}^{-2}\end{array}$ & $\begin{array}{c}\text { Flaming Phase } \\
\text { Consumption, } \\
\%\end{array}$ \\
\hline Tropical forest & 30. & 80. & 45 \\
Woody savanna - cerrado & 4.4 & 23. & 75 \\
Grassland - pasture - cropland & 3.3 & & 97 \\
\hline
\end{tabular}



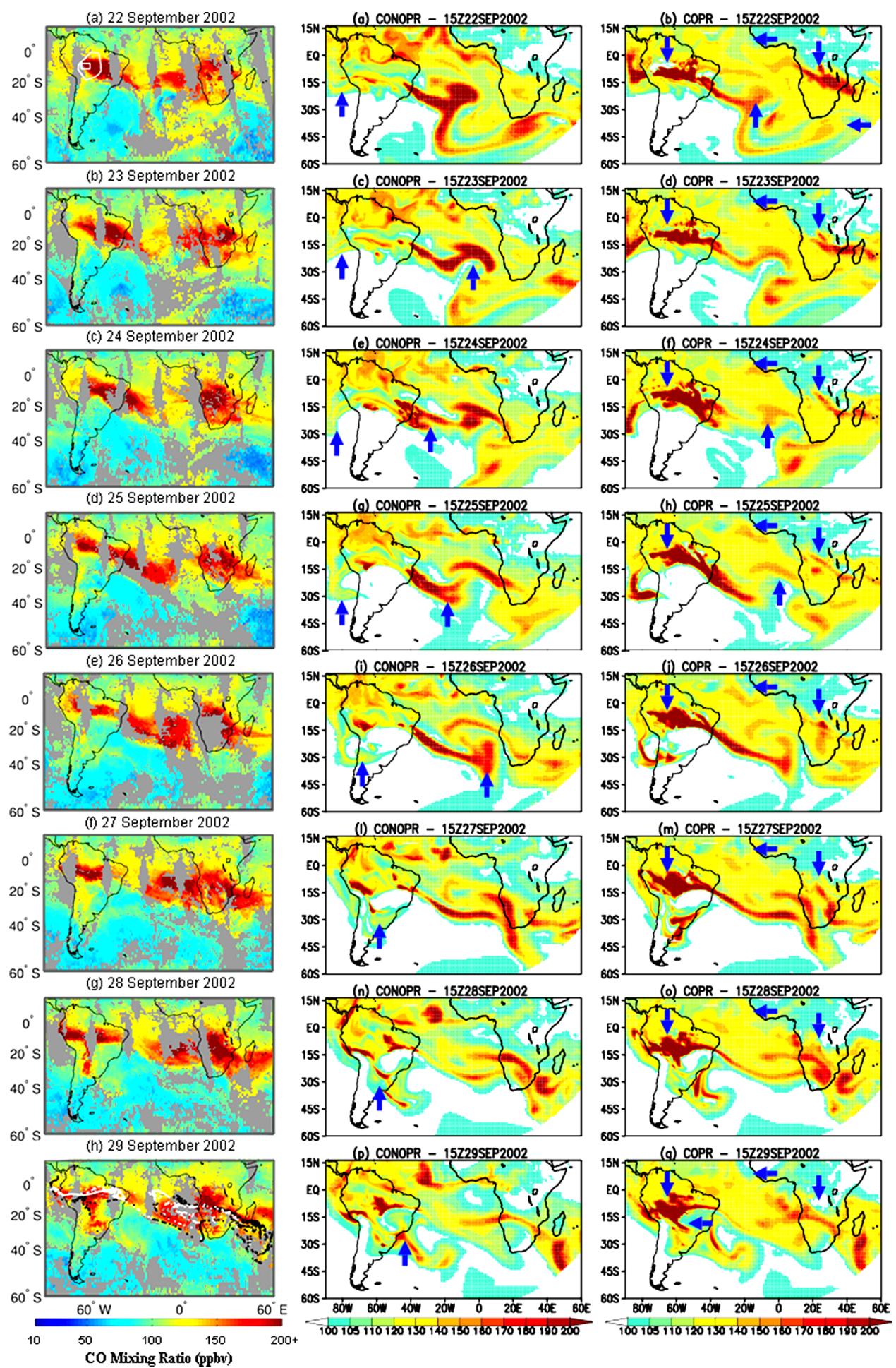

Figure 2. (left) AIRS $500 \mathrm{hPa} \mathrm{CO}$ retrievals, from 22 to 29 September 2002 (adapted from McMillan et al. [2005]). (middle, right) Model simulations of CONOPR and COPR (ppb) both at $5.9 \mathrm{~km}$ above the surface.

vational data and satellite retrievals. The model configuration had 2 grids: the coarse grid with $140 \mathrm{~km}$ horizontal resolution covering the South American and African continents, and the nested grid with a horizontal resolution of $35 \mathrm{~km}$, covering only South America. The vertical resolution for both grids was between 150 and $850 \mathrm{~m}$, with the top of the model at $23 \mathrm{~km}$ (42 vertical levels). The time integration was 135 days, starting at $00 \mathrm{Z}$ on 15 July 2002. For atmospheric initial and boundary conditions, the 6 hourly CPTEC T126 analysis field was used by means of a 4DDA technique. Two tracer variants were simulated, (1) carbon monoxide (COPR) emitted by a 3D source that includes the plume rise mechanism, and (2) carbon monoxide (CONOPR) without this mechanism and with all the emission released in the first model level. The same total mass was emitted for both tracers and they were initialized with the same back- 

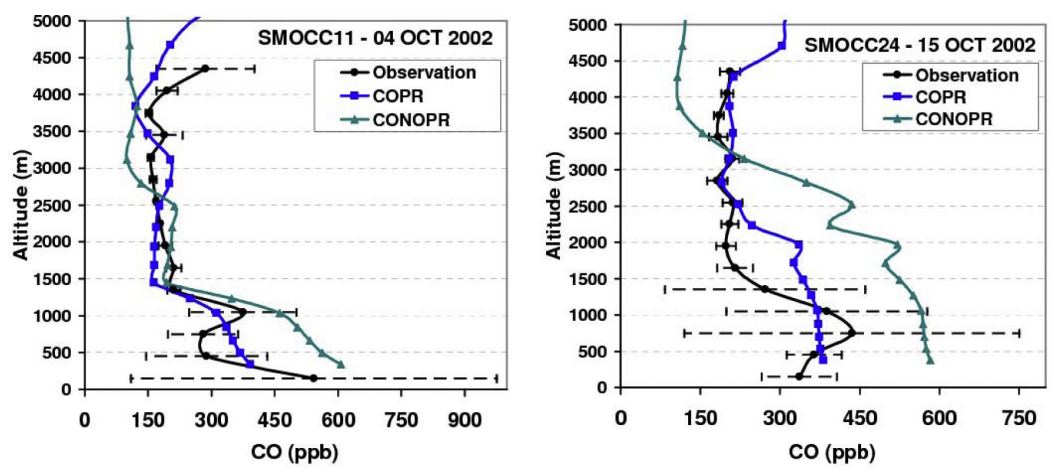

Figure 3. Comparison between CO (ppb) observed during SMOCC flights 11 and 24 (black) and model results with plume rise (COPR, blue) and without (CONOPR, green).

ground values. The total amount of the biomass burning emissions was calculated using the Brazilian Fire Emission Model (BFEMO [Freitas et al., 2005]).

\subsection{Model Comparisons With Remote Sensing Products}

[13] Figure 2 shows the tropospheric $\mathrm{CO}$ mixing ratio (ppb) retrievals from the Atmospheric InfraRed Sounder (AIRS) onboard NASA's Aqua satellite [McMillan et al., 2005] from 22 to 29 September 2002 at $500 \mathrm{hPa}$. Figure 2 also shows model results for the tracers CONOPR (at center) and COPR (at right) at $5.9 \mathrm{~km}$ height above the surface for the same dates. In this case, the smoke distribution over South America and the South Atlantic Ocean was synoptically governed by a cold front approaching from the south on 22 September, pushing the fire emissions in central Brazil and on the border of Amazônia towards to the northern and northeastern regions of South America. On 26 September, with the weakening of the cold front, the anticyclonic circulation recovers its position over central Brazil with a meridional flow from the north bringing smoke to the southern region of South America. In order to evaluate the CONOPR and COPR performances, five regions were considered: (1) over the Amazon basin and central part of South America; (2) over the mid-Atlantic Ocean; (3) over the region between the equator and $15^{\circ} \mathrm{N}$; (4) over southern Africa, and (5) the outflow region to the Pacific Ocean and recirculation over South America. The 'blue arrows' in the plots indicate which simulation results compared best with AIRS CO. Over the Amazon basin and the central part of Brazil the COPR results systematically reproduced the AIRS CO pattern better than CONOPR. However, for the South American southeast outflow to the Atlantic Ocean the skill of both simulations is not well defined. Over the northern part of the model domain, between the equator and $15^{\circ} \mathrm{N}$, again, COPR has a notable superiority. CONOPR over this region presents pronounced higher concentrations than AIRS CO, while COPR shows a smoother pattern with less $\mathrm{CO}$ and is more consistent with AIRS data. The outflow to the Pacific Ocean also has no clear definition about which model did better. On this aspect, for 22 September, the COPR is over-predicted while CONOPR is under predicted, but, on 25,27 and 29 September, both simulations did well. Over the southern Africa and its southeastern outflow, neither model simulation performed as well as for South America and neighbor- ing areas. The main reasons for this are the much poorer information about the sources and the lower model resolution over the African Continent when compared to South America. Also, there is a lack of appropriate lateral boundary conditions at the northeast part of the model domain. Because relevant data are lacking, the model could not be supplied with emissions from Asian fires, which show up in the AIRS CO. In spite of these limitations, COPR results are more consistent with AIRS CO than CONOPR. Improvements for our African source estimation are under development and should produce model simulations much more comparable with AIRS data, not only over the African continent, but also over Atlantic Ocean neighboring areas.

[14] Judging from Figure 2 (22 to 26 September), CONOPR seems to favor a higher concentration of pollutants in regions far from the sources, which should not be the case. Long-range transport to the mid-Atlantic Ocean and western coast of Africa shown here was strongly associated with the approach of the cold front. This synoptic scale system vented the higher PBL CONOPR concentrations upward (see Figure 3), which were subsequently carried out over the Atlantic Ocean by mid-level westerly jets. However, for 22, 24 and 25 September the pollutant concentrations are overpredicted in reference to AIRS CO, while COPR seems to be more realistic. For 23 to 26 September, there are some features over these areas that were marginally better simulated by CONOPR than COPR.

[15] Nevertheless, in general, the model performance of COPR is superior to the CONOPR on the reproducibility of AIRS CO retrieval and demonstrates clearly the importance of the plume rise mechanism and of an accurate representation of smoke injection height on the simulation of $\mathrm{CO}$ in the mid-troposphere.

\subsection{Model Comparisons With Observed CO Profiles During the SMOCC Campaign}

[16] Comparison of simulated CO profiles in the PBL and lower troposphere were performed using airborne measurements from the SMOCC campaign [Andreae et al., 2004]. The airborne part of SMOCC took place in the Amazon Basin during September and October of 2002. Figure 3 shows comparisons for Flights 11 and 24, on 04 and 15 October 2002, respectively. The mean and standard deviations (STD) of the observed CO profiles are shown; note that STD represents the actual variability of the concentrations, not the measurement error. The observed 
CO profiles show the high variability inside the PBL $(<1.5 \mathrm{~km})$ associated with local plumes, which can not be resolved by the model. Above the PBL and below $3 \mathrm{~km}$ there was a relatively clean layer, with only a minor haze layer with about $200 \mathrm{ppb} \mathrm{CO}$. However, above $3 \mathrm{~km} \mathrm{CO}$ starts to increase with height on Flight 11, reaching ca. $350 \mathrm{ppb}$ at about $4.5 \mathrm{~km}$, the typical maximum altitude reached by the SMOCC aircraft. During almost all flights in the dry season, haze layers resulting from the detrainment of smoke from convective clouds were visually observed at this height level, and also well above the aircraft ceiling altitude. Model COPR agrees very well with the observed CO profile, being inside the variability range in the PBL, and following very closely the $\mathrm{CO}$ distribution in the lower troposphere. Model CONOPR over-predicts CO in the PBL, and simulates too clean a lower troposphere. For Flight 24 the results are very similar, confirming the importance of the inclusion of the convective plume rise mechanism.

\section{Conclusions}

[17] We have shown the need to consider the sub-grid transport associated with convection due to the initial buoyancy of the smoke emitted during vegetation fires. Model results indicate that this mechanism is of crucial importance in order to have a realistic 3D distribution with an accurate representation of the injection height of biomass burning pollution in the atmosphere. The methodology presented here provides a powerful and feasible approach to include this mechanism in low resolution atmospheric transportchemistry models.

[18] Acknowledgments. We thank M. Welling for his help obtaining the CO data and Don Latham for the first version of the 1D plume model. We acknowledge partial support of this work by NASA Headquarters (NRA-03-OES-02 and NRA-02-OES-06). This work was carried out within the framework of the project "Monitoramento de emissões de queimadas e avaliação das observações de qualidade do ar em Três Lagoas - MS" in collaboration with CENPES/Petrobras; the LBA Smoke, Aerosols, Clouds, Rainfall, and Climate (SMOCC) project (funded by the Environmental and Climate Program of the European Commission under contract EVK2-CT2001-00110-SMOCC and by the Max Planck Society), and Radiation, Cloud, and Climate Interactions in the Amazon during the DRY-TO-WET Transition Season (RACCI) project. The authors also thank the anonymous reviewers for their very constructive comments.

\section{References}

Andreae, M. O., et al. (2001), Transport of biomass burning smoke to the upper troposphere by deep convection in the equatorial region, Geophys. Res. Lett., 28(6), 951-954.

Andreae, M. O., D. Rosenfeld, P. Artaxo, A. Costa, G. Frank, K. Longo, and M. Silva Dias (2004), Smoking rain clouds over the Amazon, Science, 303, 1342-1345.

Berry, E. X. (1968), Modification of the warm rain process, paper presented at 1 st National Conference on Weather Modification, Am. Meteorol. Soc., Albany, N. Y.

Carvalho, J. A., Jr., J. M. Santos, J. C. Santos, M. M. Leitão, and N. Niguchi (1995), A tropical rainforest clearing experiment by biomass burning in the Manaus region, Atmos. Environ., 29, 2301-2309.

Carvalho, J. A., Jr., F. S. Costa, C. A. Gurgel Veras, D. V. Sandberg, E. C. Alvarado, R. Gielow, A. M. Serra Jr., and J. C. Santos (2001), Biomass fire consumption and carbon release rates of rainforest-clearing experiments conducted in northern Mato Grosso, Brazil, J. Geophys. Res., 106(D16), 17,877-17,888.

Colarco, P. R., M. R. Schoeberl, B. G. Doddridge, L. T. Marufu, O. Torres, and E. J. Welton (2004), Transport of smoke from Canadian forest fires to the surface near Washington, D.C.: Injection height, entrainment, and optical properties, J. Geophys. Res., 109, D06203, doi:10.1029/ 2003JD004248.
Ferguson, S. A., D. V. Sandberg, and R. Ottmar (2000), Modeling the effects of land use changes on global biomass emissions, in Biomass Burning and Its Interrelationships With the Climate System, edited by J. L. Innes, M. Beniston, and M. M. Verstraete, pp. 33-50, Springer, New York.

Freitas, S., K. Longo, M. Silva Dias, P. Silva Dias, R. Chatfield, E. Prins, P. Artaxo, G. Grell, and F. Recuero (2005), Monitoring the transport of biomass burning emissions in South America, Environ. Fluid Mech., 5(1-2), 135-167, doi:10.1007/s10652-005-0243-7.

Fromm, M. D., and R. Servranckx (2003), Transport of forest fire smoke above the tropopause by supercell convection, Geophys. Res. Lett., 30(10), 1542, doi:10.1029/2002GL016820.

Guyon, P., et al. (2005), Airborne measurements of trace gases and aerosol particle emissions from biomass burning in Amazonia, Atmos. Chem. Phys., 5, 2989-3002.

Jost, H., et al. (2004), In-situ observations of mid-latitude forest fire plumes deep in the stratosphere, Geophys. Res. Lett., 31, L11101, doi:10.1029/ 2003GL019253.

Kessler, E. (1969), On the Distribution and Continuity of Water Substance in Atmospheric Circulation Models, Meteorol. Monogr., vol. 10, Am. Meteorol. Soc., Boston, Mass.

Latham, D. (1994), PLUMP: A one-dimensional plume predictor and cloud model for fire and smoke managers, Gen. Tech. Rep. INT-GTR-314, Intermountain Res. Stn., USDA For. Serv., Washington, D. C.

Lavoué, D., C. Liousse, H. Cachier, B. J. Stocks, and J. G. Goldammer (2000), Modeling of carbonaceous particles emitted by boreal and temperature wildfires at northern latitudes, J. Geophys. Res., 105(D22), $26,871-26,890$

Luderer, G., J. Trentmann, T. Winterrath, C. Textor, M. Herzog, H.-F. Graf, and M. O. Andreae (2006), Modeling of biomass smoke injection into the lower stratosphere by a large forest fire: II. Sensitivity studies, Atmos. Chem. Phys. Discuss., 6, 6081-6124.

McCarter, R., and A. Broido (1965), Radiative and convective energy from wood crib fires, Pyrodinamics, 2, 65-85.

McMillan, W. W., C. Barnet, L. Strow, M. T. Chahine, M. L. McCourt, J. X Warner, P. C. Novelli, S. Korontzi, E. S. Maddy, and S. Datta (2005), Daily global maps of carbon monoxide from NASA's Atmospheric Infrared Sounder, Geophys. Res. Lett., 32, L11801, doi:10.1029/ 2004GL021821.

Miranda, A., H. Miranda, I. Oliveira Dias, and B. de Souza Dias (1993), Soil and air temperatures during prescribed cerrado fires in central Brazil, J. Trop. Ecol., 9, 313-320.

Morton, R., G. Taylor, and J. Turner (1956), Turbulent gravitational convection from maintained and instantaneous sources, Proc. R. Soc., Ser. A, $234,1-23$

Ogura, Y., and T. Takahashi (1971), Numerical simulation of the life cycle of a thunderstorm cell, Mon. Weather Rev., 99, 895-911.

Prins, E., J. Feltz, W. Menzel, and D. Ward (1998), An overview of GOES-8 diurnal fire and smoke results for SCAR-B and 1995 fire season in South America, J. Geophys. Res., 103(D24), 31,821-31,835.

Riggan, P., R. Tissell, R. Lockwood, J. Brass, J. Pereira, H. Miranda, A. Miranda, T. Campos, and R. Higgins (2004), Remote measurement of energy and carbon flux from wildfires in Brazil, Ecol. Appl., 14(3), 855872.

Simpson, J., and S. Wiggert (1969), Models of precipitating cumulus towers, Mon. Weather Rev., 97, 471-489.

Tremback, C., J. Powell, W. Cotton, and R. Pielke (1987), The forward in time upstream advection scheme: Extension to higher orders, Mon. Weather Rev., 115, 540-555.

Trentmann, J., M. O. Andreae, H.-F. Graf, P. V. Hobbs, R. D. Ottmar, and T. Trautmann (2002), Simulation of a biomass-burning plume: Comparison of model results with observations, J. Geophys. Res., 107(D2), 4013, doi: $10.1029 / 2001$ JD000410.

Turner, J. S. (1973), Buoyancy Effects in Fluids, 368 pp., Cambridge Univ. Press, New York.

Ward, D. E., R. A. Susott, J. B. Kauffman, R. E. Babbit, D. L. Cummings, B. Dias, B. N. Holben, Y. J. Kaufman, R. A. Rasmussen, and A. W. Setzer (1992), Smoke and fire characteristics for Cerrado and deforestation burns in Brazil: BASE-B experiment, J. Geophys. Res., 97(D13), $14,601-14,619$.

M. O. Andreae, Max Planck Institute for Chemistry, D-55020 Mainz, Germany.

S. R. Freitas and K. M. Longo, Center for Weather Forecasting and Climate Studies, Instituto Nacional de Pesquisas Espaciais, Rodovia Presidente Dutra km 39, Cachoeira Paulista 12630-000 Sao Paulo, Brazil. (sfreitas@cptec.inpe.br) 